\title{
Particle capture and processing mechanisms in Sabellaria alveolata (Polychaeta: Sabellariidae)
}

\author{
Stanislas Dubois ${ }^{1,2, *}$, Laurent Barillé ${ }^{1}$, Bruno Cognie ${ }^{1}$, Peter G. Beninger ${ }^{1}$ \\ ${ }^{1}$ Laboratoire de Biologie Marine, UPRES-EA 2663, Faculté des Sciences, Université de Nantes, 44322 Nantes cedex 3, France \\ ${ }^{2}$ Present address: Laboratoire de Biologie et Biotechnologies Marines, Université de Caen, 14032 Caen cedex, France
}

\begin{abstract}
Sabellaria alveolata, a ciliary suspension feeder, is a reef-building polychaete widely distributed in European waters, and is an important element of the trophic web of the ecosystems they have colonised. The lack of data concerning the feeding mechanisms of polychaete sabellariids is an impediment to understanding their roles in these systems. In this study, we combine a descriptive approach based on SEM observations and histological mapping of mucocytes with video endoscopic recordings to provide a functional interpretation of particle capture and processing mechanisms. It is hypothesised that particle capture in $S$. alveolata is based on the beat of grouped cilia. The cilia types and distributions of tentacles are described, and both downstream and upstream collecting mechanisms are demonstrated in this species. Other feeding characteristics, such as the flicking of tentacles, are involved in particle capture. Feeding mechanisms suggest previously unsuspected similarities with lophophorids. The role of mucus in $S$. alveolata was characterised in the tentacles, grooves and buccal cavity, and the functional specialisation of organs in transport or rejection of particles was confirmed with video recordings. Tentacles and grooves collect and transport particles towards the mouth, and only viscous acid mucopolysaccharide-secreting mucocytes occurred on these organs, protecting particles from being removed with currents. The presence of mixed mucocytes on the cephalic floor, situated just posterior to the mouth, suggests that this area is involved in rejection of pseudofaeces. The implications of these results are discussed in terms of environmental adaptation and are compared to other families of ciliary suspension-feeding polychaetes.
\end{abstract}

KEY WORDS: Ciliary filter feeder $\cdot$ Particle capture $\cdot$ Processing mechanisms $\cdot$ Sabellaria alveolata Polychaete

\section{INTRODUCTION}

Contemporary research has paid increasing attention to the principles of particle capture and processing mechanisms in suspension-feeding animals using ciliary bands to drive fluid motion. Bivalves represent the most studied group, mainly for economic reasons, linked with the continuing development of shellfish farming worldwide. Less information is available concerning ciliary filter-feeding polychaetes, despite their suspected functional role in trophic webs (Fauchald \& Jumars 1979). Nevertheless, water processing, velocities and capture of particle have been studied in sabellids (Jørgensen et al. 1984, Mayer 1994, 2000) and ser- pulids (Riisgård et al. 2000, 2002) by means of video observations and measurements of filtration rate and retention efficiencies. No data concerning the mechanisms of particle capture are available for sabellariids, although they are considered ciliary filter feeders and very close to sabellids and serpulids in terms of an evolutionary trend in feeding organs (Rouse \& Fauchald 1997). Far less attention has been paid to other aspects of filter-feeding, such as mucus retention and handling, considered to be of primary importance in physical models of particle retention in tentaculate suspension feeders, also classified as ciliarymucoid feeders (Jørgensen et al. 1984, Shimeta \& Koehl 1997). 
The polychaete Sabellaria alveolata (L.) is a common species occurring on the coast, from Ireland and England to Morocco (Gruet 1982). In fact, it is the most common sabellariid species in European coastal waters (Pawlick 1988). This gregarious species lives in a tube of sand built of selected inorganic particles (Gruet 1984): the association of tubes leads to the formation of biogenic reefs, which can cover several hectares on intertidal sandflats. $S$. alveolata is responsible for the largest reef formations in temperate regions (Holt et al. 1998), mainly located on the French coast in the Bay of Mont-Saint-Michel (English Channel coast) and in Bourgneuf Bay (Atlantic coast). A dual competition for space and food occurs in these shellfish ecosystems between cultivated oysters (Crassostrea gigas) and the polychaete $S$. alveolata (Dubois et al. 2003), with adult densities of this polychaete reaching $>35000$ ind. $\mathrm{m}^{-2}$ (Dubois et al. 2002).

The anatomy of the feeding organs of sabellariids has been partly described by Johansson (1927) and Wells (1970) (Fig. 1), but no information has been given about the structure of the ciliated band found in the tentacles or the mechanisms of capture and transport of particles. Recent ecophysiological studies have shown that Sabellaria alveolata is able to efficiently retain particles $>4 \mu \mathrm{m}$, in equivalent spherical diameter, and the individual clearance rate has been assessed at $7.5 \times 10^{-4} 1 \mathrm{~h}^{-1}$ (Dubois et al. 2003). The particle collecting system is represented by tentacles (approx. 250 for adults) extended from the tube (tentacle length $\times 1 \mathrm{~cm}$ ). Although it is impossible to estimate the porosity of such a dynamic filtering system, the
$100 \%$ retention of some smaller particle sizes suggests that capture mechanisms other than direct interception are at work (Rubenstein \& Koehl 1977). Two types of capture mechanisms have been recognised in ciliary filter-feeding polychaetes, according to the position of individuals in their tube (Jørgensen et al. 1984, Riisgård \& Larsen 1995, 2000, Riisgård et al. 2000, 2002): downstream and upstream collecting, whereby particles are collected, respectively, on the downstream or on the upstream side of the current-generating ciliary band.

We used complementary investigative techniques to elucidate particle capture, retention and handling mechanisms from the tentacles to the mouth in Sabellaria alveolata. In this effort, scanning electron microscopic has been combined with direct observations of tentacle and groove functioning using videoendoscopy (e.g. Ward et al. 1991, 1993, Beninger et al. 1992, 2004, Cognie et al. 2003). Mapping of the cilia and mucocytes of the feeding organs has provided powerful inferential information on particle processing in bivalves (e.g. Beninger \& Dufour 1996, Beninger \& Saint-Jean 1997a,b, Beninger et al. 2003). To our knowledge, mapping has never been performed in ciliary suspension-feeding polychaetes; we present the results of such work herein.

A secondary objective was to compare the feeding mechanisms in sabellariids with those involved in close families, such as sabellids and serpulids. From a fundamental point of view, an in-depth understanding of feeding mechanisms and the transport of particles is necessary to illuminate convergences or differences in

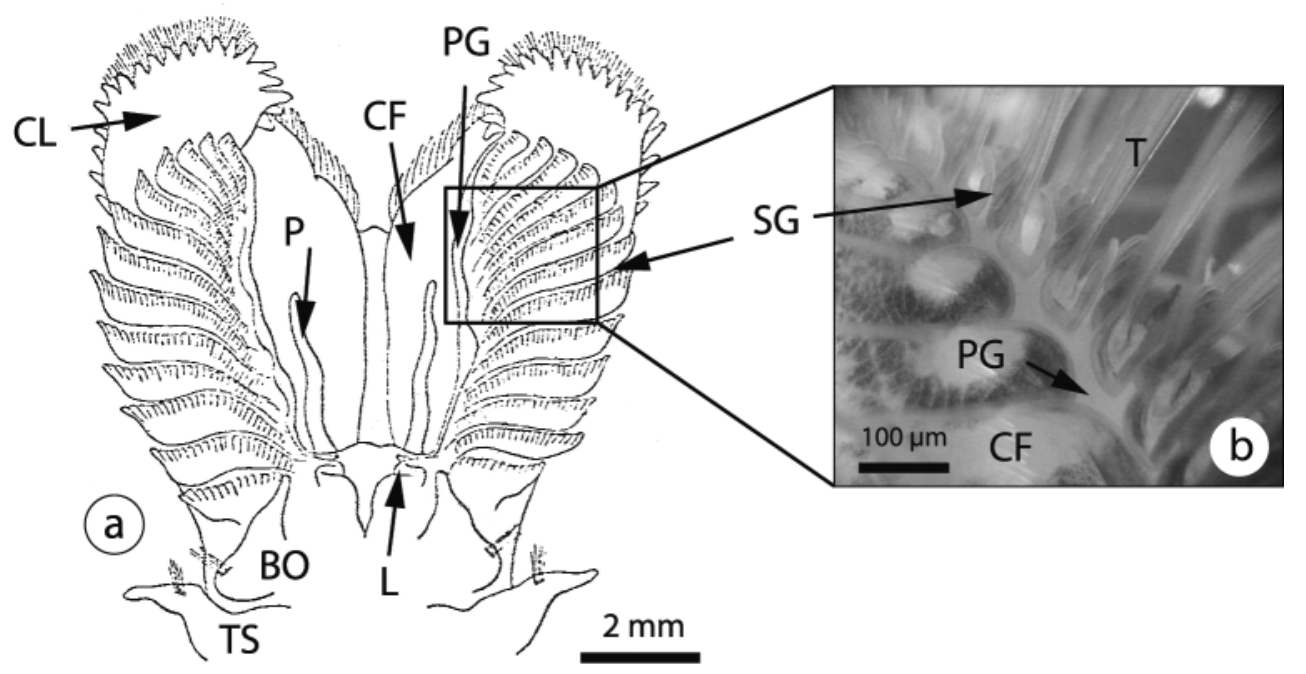

Fig. 1. Sabellaria alveolata. (a) Diagram of anterior region viewed from ventral (tentacles not shown). The feeding organ is composed of 2 parts inserted ventrally on 2 cephalic ventral lobes (CL). On each lobe, a primary groove (PG) collects particles and small grain sand to be conducted to the mouth. Each of the 2 primary grooves is divided into secondary grooves (SG). Two palps (P) are ventrally inserted behind the upper lips. (b) Photograph of living individual showing tentacles (T) inserted on the border of secondary grooves. When the worm is feeding, tentacles are erected in the water column above the aperture of the tube. $\mathrm{BO}$, building organ; $\mathrm{CF}$, cephalic floor; L, internal and external lips; TS, first thoracic segment 
the evolution of suspension-feeding systems. From an ecological standpoint, this study will help in the interpretation of the large geographical range and apparent adaptational plasticity of Sabellaria alveolata, which is found in coastal habitats displaying a wide range of inorganic seston concentrations.

\section{MATERIALS AND METHODS}

Specimen sampling and maintenance. Reef portions of Sabellaria alveolata were collected in February 2004 in Bourgneuf Bay, Atlantic coast $\left(46^{\circ} 54.2^{\prime} \mathrm{N}\right.$, $\left.02^{\circ} 10.3^{\prime} \mathrm{W}\right)$, using a metal corer specially designed for reef sampling (Dubois et al. 2002). They were placed in a thermo-constant room with running seawater $\left(34 \mathrm{psu}_{;} 13^{\circ} \mathrm{C}\right)$. For stabilisation in the laboratory, the worms were fed with a live algal culture of Skeletonema costatum and kept for several days in constant conditions before experiments.

Scanning electron microscopy (SEM). Some specimens were extracted from their tubes and carefully washed in seawater to eliminate a maximum of mud and small particles from the opercular crown. They were narcotised with increasing concentrations of $7.5 \% \mathrm{MgCl}_{2}$ in filtered seawater $(63 \mu \mathrm{m})$ and placed in a solution of $2.5 \%$ glutaraldehyde in a slightly hyperosmotic, $0.1 \mathrm{M}$ sodium cacodylate buffer (Beninger et al. 1995). An alternative method to the critical point drying (CPD) technique (Boyde \& Wood 1969) was tested here for SEM preparation, consisting of airdrying of specimens by the evaporation of hexamethyldisilazane (HMDS). HMDS has been evaluated as better than CPD for SEM observations of many biological samples (see, for example, Nation 1983, Hochberg \& Litvaitis 2000). Photographs were obtained with the SEM JEOL 6400F of the University of Nantes.

Additional measurements of tentacles and laterally grouped cilia were performed on living individuals, using a microscope with a calibrated optical scale, in order to assess artefactual shrinkage due to this technique. All measurements made on SEM preparations have been corrected in this manner.

Histological and whole-mount staining. Narcotised specimens were placed in aqueous Bouin's fixative (Martoja \& Martoja 1967). Worms were sectioned between the cephalon and the thorax. The cephalic parts were processed histologically and embedded in paraffin. Thick transverse and longitudinal sections $(6 \mu \mathrm{m})$ were stained in periodic acid-Schiff-Alcian blue (PAS-AB; Beninger et al. 1993, 2003, Beninger \& Saint-Jean 1997a,b), with modified staining times: $1 \mathrm{~min}$ in Alcian blue, $1 \mathrm{~min}$ in periodic acid and $3 \mathrm{~min}$ in Schiff's reagent. Entire tentacles sectioned under a dissecting microscope were placed in staining cap- sules and stained with PAS-AB. Optimal staining times were $30 \mathrm{~s}$ in Alcian blue, $60 \mathrm{~s}$ in periodic acid and $90 \mathrm{~s}$ in Schiff's reagent. Sections or tentacles were mounted on a slide in aqueous medium (Gel Mount, Biomeda).

According to previous studies carried out with bivalves (Beninger \& Saint-Jean 1997a), we adopted here the standard histochemical classification of mucus secretion, wherein all mucocyte secretions are termed mucopolysaccharides (MPS), and are classed according to their degree of acidity. Neutral MPS (NM) are PAS-positive and Alcian blue negative, and present low viscosity. Acid MPS (AM) are PAS-negative and Alcian blue positive, and present high viscosity. Between these 2 endpoints, we distinguished mixed MPS (MM), containing approximately equal proportions of NM and AM.

Counts of each type of mucocyte were performed along a length of $100 \mu \mathrm{m}$, calculated with microscopic image analysis software (Lucia G. Nikon Software). Ten randomly chosen parts of tentacles or grooves were analysed. To allow for comparison with data from the row-extensive bivalve literature, results are presented as the mean density along a tentacle length of $100 \mu \mathrm{m}$ or a portion of the groove (primary or secondary) of $100 \mu \mathrm{m}$. Examination of the whole mounts showed the presence of only 1 pyriform mucocyte type. To give a better idea of each type's contribution to the mucus and its consequent viscosity, the maximal width was determined with microscopic image analysis software from 30 mucocytes of each type and in each counting zone.

ANOVA tests were used to test for differences in mucocyte density and size. Data were $\log _{\mathrm{e}}$-transformed, and Bartlett's test was used to test for homogeneity of variance. The Student-Newman-Keuls' (SNK) test was used for multiple comparisons. A significance level of $\mathrm{p}<0.05$ was used in all tests.

Video observations. Tubes were isolated from reef portions and placed in transparent plastic chambers with open-circuit seawater flow. Some specimens were carefully extracted from their tube and placed in a plastic tube (diameter $5 \mathrm{~mm}$ ) that could easily be orientated in the chambers. Flow speed was considered as unidirectional (Barillé et al. 1993) and adjusted to $50 \mathrm{ml}$ $\mathrm{s}^{-1}$ with Gilmont flowmeters. Endoscopy was performed according to the general procedure of Ward et al. (1991) and Beninger et al. (1992), but with a larger optical tube (OT) of $8 \mathrm{~mm}$ (Schoelly Rigid Borescope $8 \mathrm{~mm} \times 240 \mathrm{~mm}$ ). Sabellaria alveolata is a small polychaete species, and observation of tentacles and particle capture required a greater magnitude than that provided by 1.7 or $4 \mathrm{~mm} \mathrm{OT}$, classically used in the latest endoscopy studies (Cognie et al. 2003, Beninger et al. 2004). Furthermore, all feeding structures are 
deployed externally, so a small OT is not necessary. Other light sources were added to offset the lack of luminosity due to a wider optical aperture. The OT was connected to a colour camera (Sony Hyper HAD, CCDIRIS/RGB) via an optical adapter. The camera was directed by a micromanipulator, enabling displacement of the OT. Video sequences were digitised and stored directly on a computer using a miroDC1000 video card (Pinnacle Systems) and Adobe Premiere 6.5 image software (Adobe Systems).

The microalgal species used were maintained in the Nantes Culture Collection (NCC, see Beninger et al. 2004 for culture conditions). Particle sizes were determined with a Multisizer particle counter and expressed as equivalent spherical diameter (ESD). Experiments were performed with a diet of Coscinodiscus granii (NCC11 - modal size $18 \mu \mathrm{m}$ ESD) at a concentration of $5 \times 10^{3}$ cells ml ${ }^{-1}$. To test for feeding behavioural differences under higher particle concentrations, 2 algae (Skeletonema costatum, NCC 60 -modal size $10 \mu \mathrm{m}$ ESD, and Thalassiosira sp., NCC 63-modal size $11 \mu \mathrm{m}$ ESD) were added to the algal culture until $4 \times 10^{5}$ cells $\mathrm{ml}^{-1}$. Inorganic particles (graphite suspension or reflecting particles - from 2 to $20 \mu \mathrm{m}$ ESD) were added qualitatively to the experimental chambers for complementary observations. Recordings were made under very similar temperature conditions $\left(15^{\circ} \mathrm{C}\right)$. The colour of the background was modified according to particles to accentuate the contrast: a white background for dark particles (C. granii and graphite particles) and black for reflecting particles.

Additional video recordings were made under a light microscope to complete and detail recordings obtained with the OT, especially movements of groups of cilia. Portions of the cephalic part of Sabellaria alveolata, including tentacles, were obtained from living specimens under a dissecting microscope. Tentacles were placed on concave microscope slides containing seawater and Coscinodiscus granii cells at $5 \times 10^{3}$ cells $\mathrm{ml}^{-1}$. The microscope objective was linked to a camera in the same way as for endoscopy.

For a proper understanding of the anatomical terms relating to Sabellaria alveolata feeding structures, the frontal surface is herein defined as the ciliated surface, irrespective of orientation in surrounding currents.

\section{RESULTS}

\section{Morphology and ciliation of feeding organs}

Sabellaria alveolata collects particles using tentacles (10 mm length; Fig. 2a) extended in the water column at about $1.5 \mathrm{~cm}$ above the aperture of its tube. Worms generally face prevailing currents, and the frontal cili- ated surface of tentacles is thus not directly exposed (Fig. 2a,b). SEM observations revealed that each tentacle has a width of 55 to $60 \mu \mathrm{m}$ and possesses a ciliation pattern which is the same in the distal, median and proximal regions. Two surfaces can be distinguished: a ciliated frontal surface and an abfrontal surface that appears unciliated (Fig. 2b). Each filament possesses a wide row of $10 \mu \mathrm{m}$ frontal cilia (Fig. 2c) and has 2 rows of $40 \mu \mathrm{m}$ long grouped lateral cilia, inserted on each side of the tentacle and regularly spaced every $25 \mu \mathrm{m}$ (Fig. 2e,f). Among the band of frontal cilia, $22 \mu \mathrm{m}$ widely scattered grouped cilia can be distinguished (Fig. 2d). Between the frontal cilia, secretory pores of mucus cells are visible (Fig. 3a). The distal ends of the filaments contain numerous dehydrated mucus balls (Fig. 3b). A close-up of the abfrontal surface shows scattered tufts of $5 \mu \mathrm{m}$ small cilia (Figs. $2 \mathrm{~b} \& 3 \mathrm{c}$ ). The mouth and lips of $S$. alveolata are also covered by tufts of cilia from 6 to $15 \mu \mathrm{m}$ long (Fig. 3e), which are denser and longer close to the opening of the mouth. The 2 palps inserted ventrally close to the mouth are shorter (approx. 7 to $8 \mathrm{~mm}$ ) and broader than filaments $(120 \mu \mathrm{m}$ at the proximal part and $60 \mu \mathrm{m}$ at the distal part for adults), but the pattern of ciliation seems to be quite similar (Fig. 3f). The ventral floor of the cephalic lobes is densely ciliated with transversal bands of $50 \mu \mathrm{m}$ long cilia. The median band, corresponding to the junction of the lobes, seems to be unciliated, but secretory pores of mucus cells are scattered in this groove (Fig. 3d).

\section{Mucocyte distribution}

After staining with PAS-AB, 3 mucocyte types were identified. Those stained in blue (Pantone standard colours 293c, 661c and 2935c) secreted AM, those stained in purple (Pantone standard colours 249c, 2425c and 260c) secreted MM and those stained in red (Pantone standard colours 185c and 186c) secreted NM. Whole-mount and section staining of Sabellaria alveolata filaments (Fig. 4a to c) showed that only AMs are present and located under the ciliated frontal surface. The density of mucocytes is similar throughout the tentacle length, and reaches about $5.2(\mathrm{SD}=1.2)$ per $100 \mu \mathrm{m}$. A global ANOVA-SNK showed significant differences in AM densities $(\mathrm{df}=4 ; F=14.39 ; \mathrm{p} \leq 1.21$ $\times 10^{-7}$ ). There is a similar pattern in mucocyte distribution between primary and secondary grooves. The inner surface is covered by $4 \mu \mathrm{m}$ small cilia, and only AM occurred, in non-significantly different densities $(11.4 \mathrm{SD}=2.8$ for the secondary grooves and $14.8 \mathrm{SD}=$ 6.1 for the primary grooves; $\mathrm{p} \leq 0.114 ;$ Fig. 4 e,f). External borders are unciliated, and both AM and MM occurred (Fig. 4d,f). For the grooves, densities of AM 

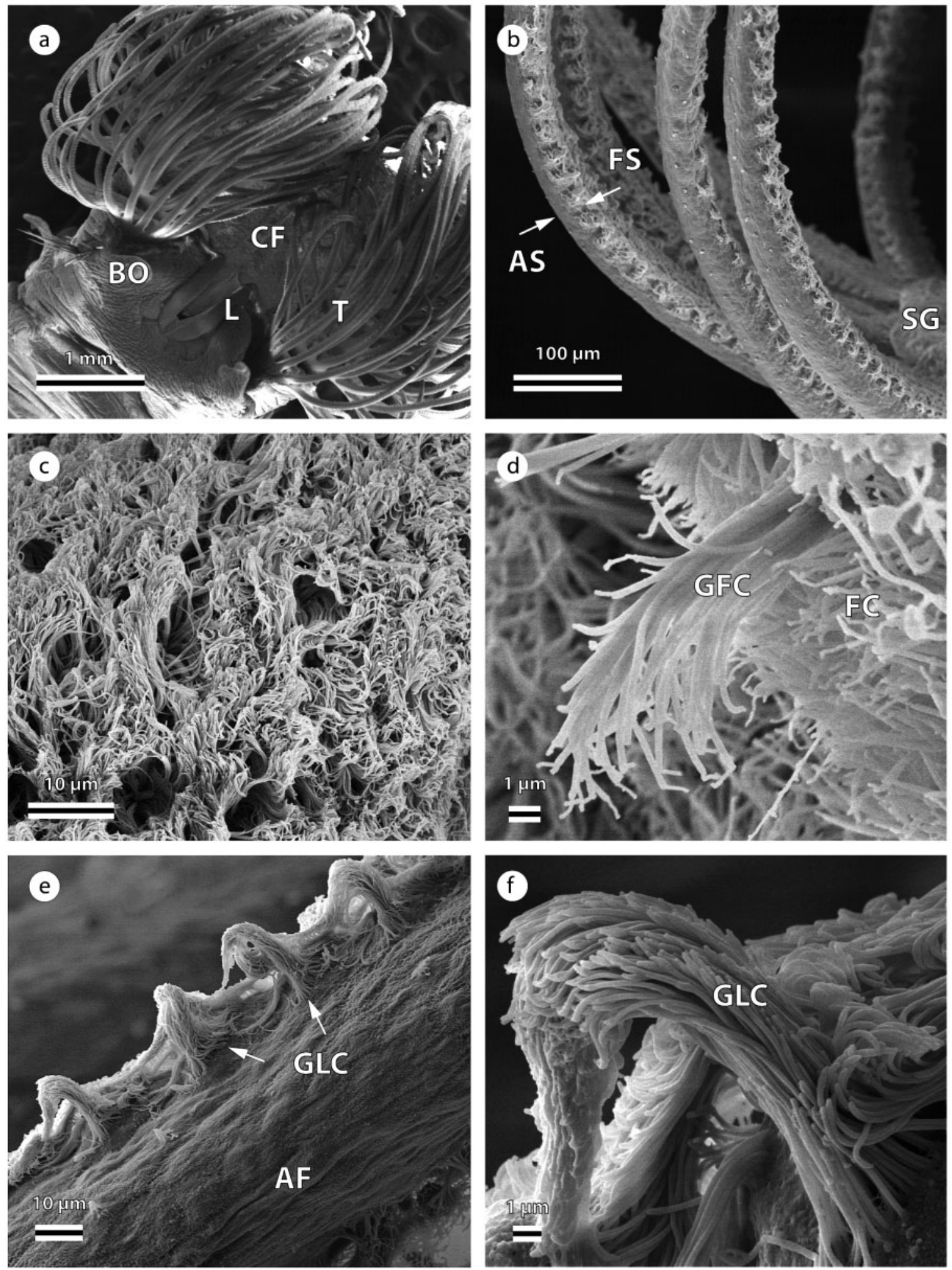

Fig. 2. Sabellaria alveolata. Scanning electron micrographs of tentacles. (a) General overview of cephalic part showing organisation of tentacles. (b) Lateral view of tentacles inserted on a secondary groove (AS, abfrontal surface; FS, frontal surface). (c) View of the motile frontal cilia of a tentacle. (d) Close-up of the frontal ciliary band showing frontal cilia (FC) and longer grouped frontal cilia (GFC). (e) Abfrontal view (AF) of a tentacle with evenly spaced, motile, grouped lateral cilia (GLC). (f) Close-up of grouped lateral cilia. Other abbreviations as in Fig. 1 

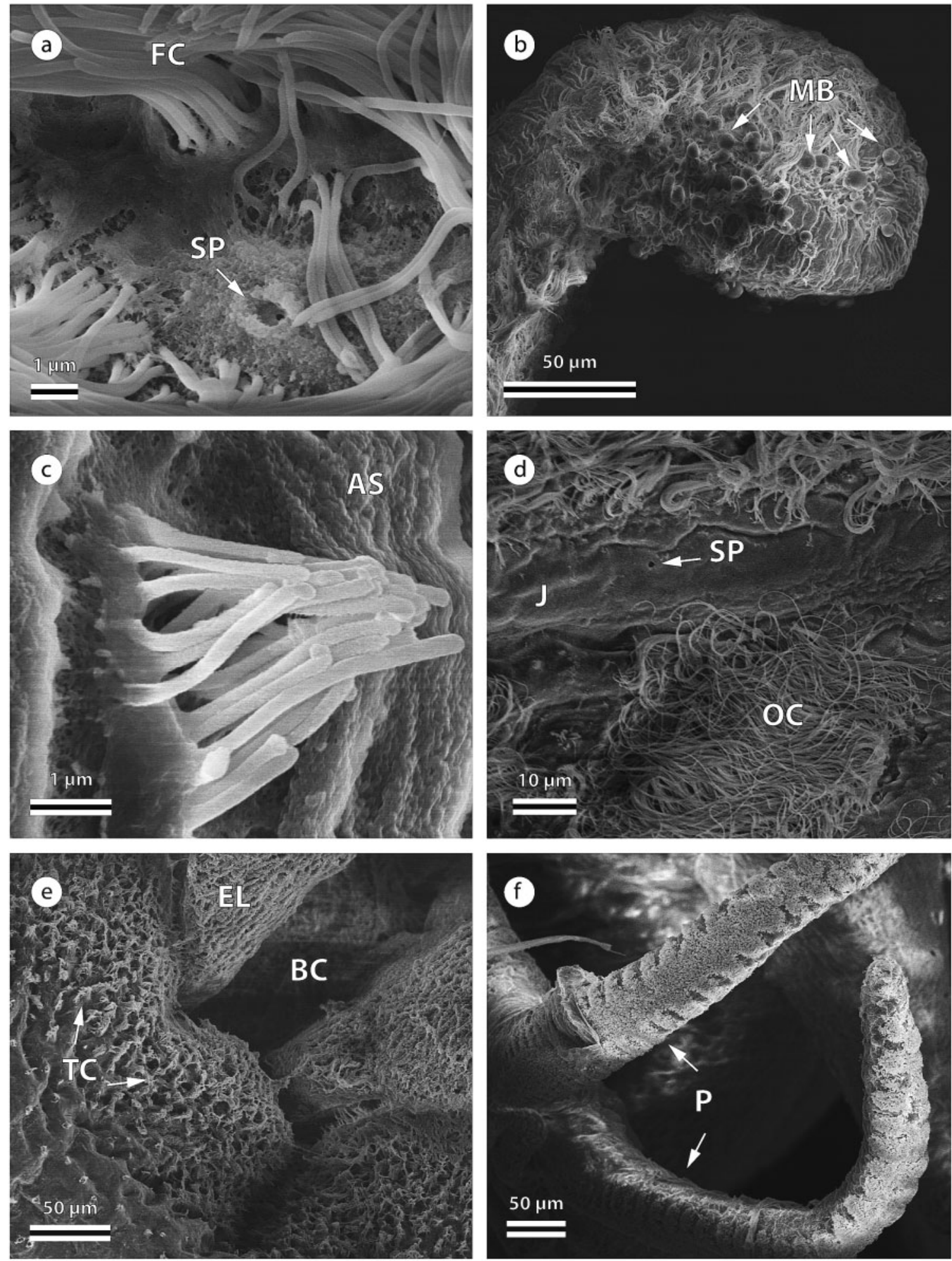

Fig. 3. Sabellaria alveolata. Scanning electron micrographs of tentacles (a-c) and buccal region (d-f). (a) Close-up of secretory pores (SP) scattered among the frontal ciliary band. (b) Lateral view of the distal tip of a tentacle showing high density of mucus balls (MB). (c) Close-up of tuft of short cilia located on the abfrontal surface. (d) Ventral view of the ciliary bands located on the cephalic floor at the junction (J) of the 2 cephalic lobes (OC, motile floor cilia). (e) Ventral view of the buccal cavity (BC) defined ventrally by external lips (EL) and widely scattered tufts of cilia (TC). (f) Lateral and frontal views of the 2 palps (P) and the pattern of the frontal ciliary band. Other abbreviations as in previous figures 

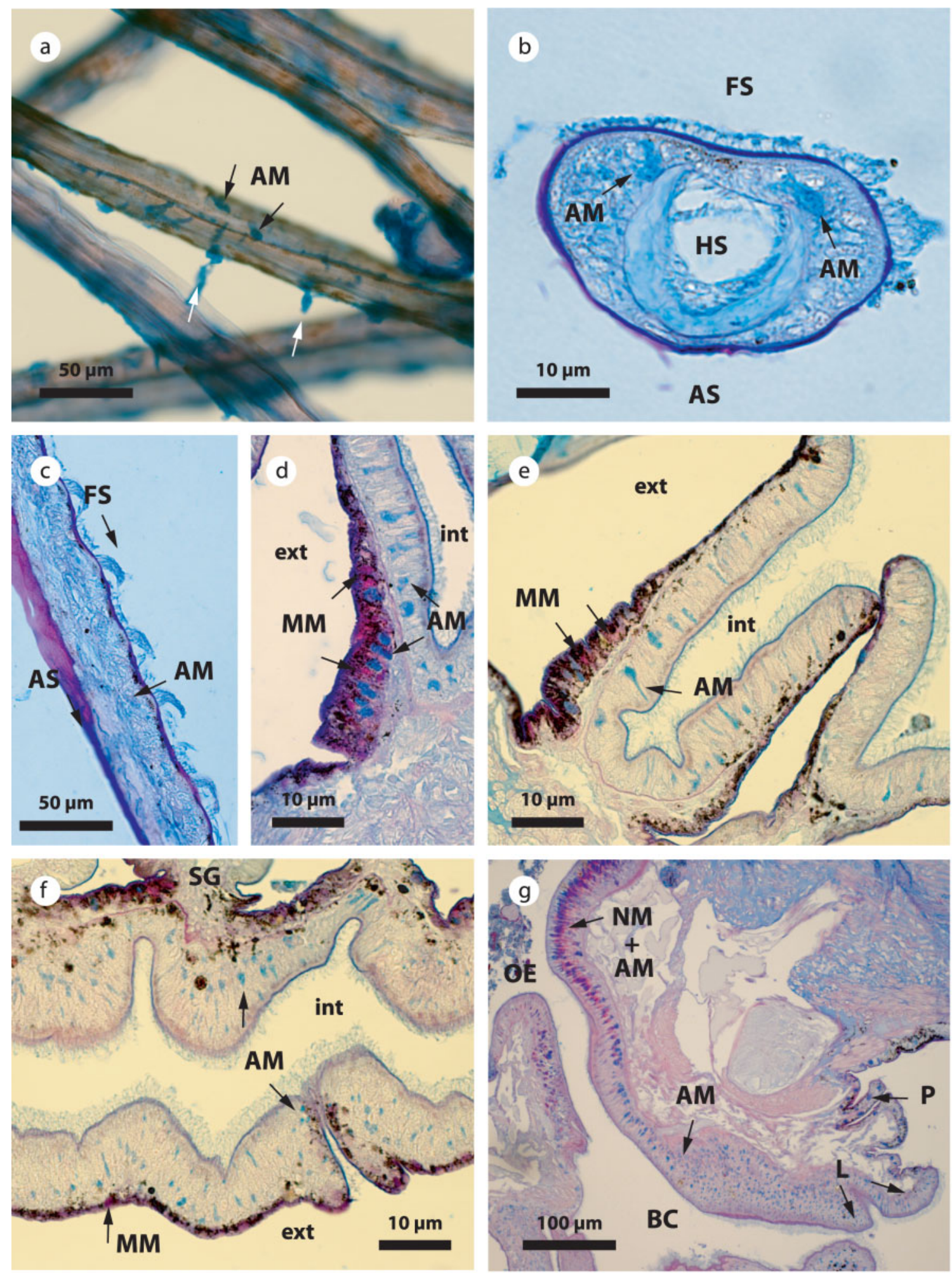

Fig. 4. Sabellaria alveolata. Whole-mount and sections of tentacles and feeding grooves stained with periodic acid-Schiff-Alcian Blue (PAS-AB). (a) Abfrontal view of whole-mount tentacles, showing only acid mucocytes (AM). Note that most mucocytes were secreting at the time of fixation (white arrows). (b) Transverse section of a tentacle showing localisation of AM exclusively on the frontal surface (FS). Note the U-shaped structure around the hydrostatic skeleton of the tentacle (HS) (AS, abfrontal surface). (c) Longitudinal section of a tentacle confirming localisation of mucocytes under frontal cilia. (d, e) Transverse sections of secondary grooves showing inner surface (int), with only AM, and exterior surface (ext), with both AM and mixed mucocytes (MM). Pigmentation of epithelia occurs only on the exterior surface of the groove. (f) Longitudinal section of the primary groove showing mucocyte distribution and cilia, with AM on the inner surface and both AM and MM on the exterior surface. (g) Longitudinal section of the buccal cavity (BC) and the upper part of the oesophagus (OE). Note the progressive change in mucocyte composition and density from AM only to both neutral mucocytes (NM) and AM in the oesophagus region ( $\mathrm{P}$, insertion of palp; $\mathrm{L}$, internal and external lips). Other abbreviations as in previous figures 
and MM are, respectively, 11.8 (SD = 3.4) and 10 (SD = 4.3) mucocytes per $100 \mu \mathrm{m}$ of secondary groove and 10.3 (SD = 2.6) and 9.2 ( $\mathrm{SD}=3.3$ ) mucocytes per $100 \mu \mathrm{m}$ of primary groove. The density of AM is significantly higher in the external borders of the secondary grooves than in those of the primary grooves $(p \leq 8 \times$ $\left.10^{-4}\right)$. MM densities are non-significantly different $(\mathrm{p} \leq$ 0.648 ), but the ratio $\mathrm{AM} / \mathrm{MM}$ is higher for primary grooves than for secondary grooves $(p \leq 0.038)$. AM and MM have the same pyriform shape, and there are no differences in mucocyte size $(\mathrm{df}=4 ; F=0.019$; $\mathrm{p} \leq$ 0.091). Thus, the most acidic mucus is secreted within the grooves, whereas the mucus secreted by the zones directly in contact with the cephalic floor is less acidic (and more fluid) because of the presence of MM.

The buccal cavity (Fig. 4g) is covered by cilia the length of which decreases from the opening of the mouth to the oesophagus (10 to 3-4 $\mu \mathrm{m}$ ). Mucocyte distribution varied from AM only to a combination of $\mathrm{AM}$ and NM at the aperture of the oesophagus.

\section{Particle capture and velocities}

Most interpretable recordings were made using low concentrations of Coscinodiscus granii $\left(5 \times 10^{3}\right.$ cells $\mathrm{ml}^{-1}$ ). Particle trajectories were analysed frame-by-frame by marking the position of the particle in focus for every second frame $(0.08 \mathrm{~s})$. Fig. 5 is an example of a particle trajectory, recorded within approximately $10 \mathrm{~s}$ and led into the ciliary current generated by the motion of grouped lateral cilia. The particle appears to accelerate exponentially towards the tentacle. At $200 \mu \mathrm{m}$ from the tentacle, velocities of particles of C. granii approaching the tentacle were measured at between 0.1 and $0.2 \mathrm{~mm}$ $\mathrm{s}^{-1}$. At $30 \mu \mathrm{m}$ from the tentacle, tip velocity was measured at 0.5 up to $2.1 \mathrm{~mm} \mathrm{~s}^{-1}$. Currents generated by ciliary motion thus provided a considerable acceleration of particles approaching the tentacles. Recordings showed that the influence of ciliary motion occurred on particles at approximately $50 \mu \mathrm{m}$ from the tentacle.

Despite the movement of the tentacles, many recordings showed regions where grouped lateral cilia were clearly visible. Two types of movement can be described. The first is a random-frequency beat, with each beat lasting $0.085 \mathrm{~s}$ (at $15^{\circ} \mathrm{C}$ ), and a metachronal wave beat, starting from the proximal part to the distal tip of the tentacle with a very variable frequency $(0.1$ to 0.5 beats $\mathrm{s}^{-1}$ ).

During the capture process, 3 types of particle capture mechanisms were recorded. These are interpreted by drawings in Fig. 6. Most frequently, the particles follow similar curved paths when approaching the tentacle, as illustrated in Fig. 6a. This corresponds to downstream particle retention: particles that arrive behind the tentacle and enter the region swept by grouped lateral cilia are deviated in a curved path through the frontal ciliary band. It was not possible to determine whether physical contact was established between the particle and lateral cilia in their effective stroke.
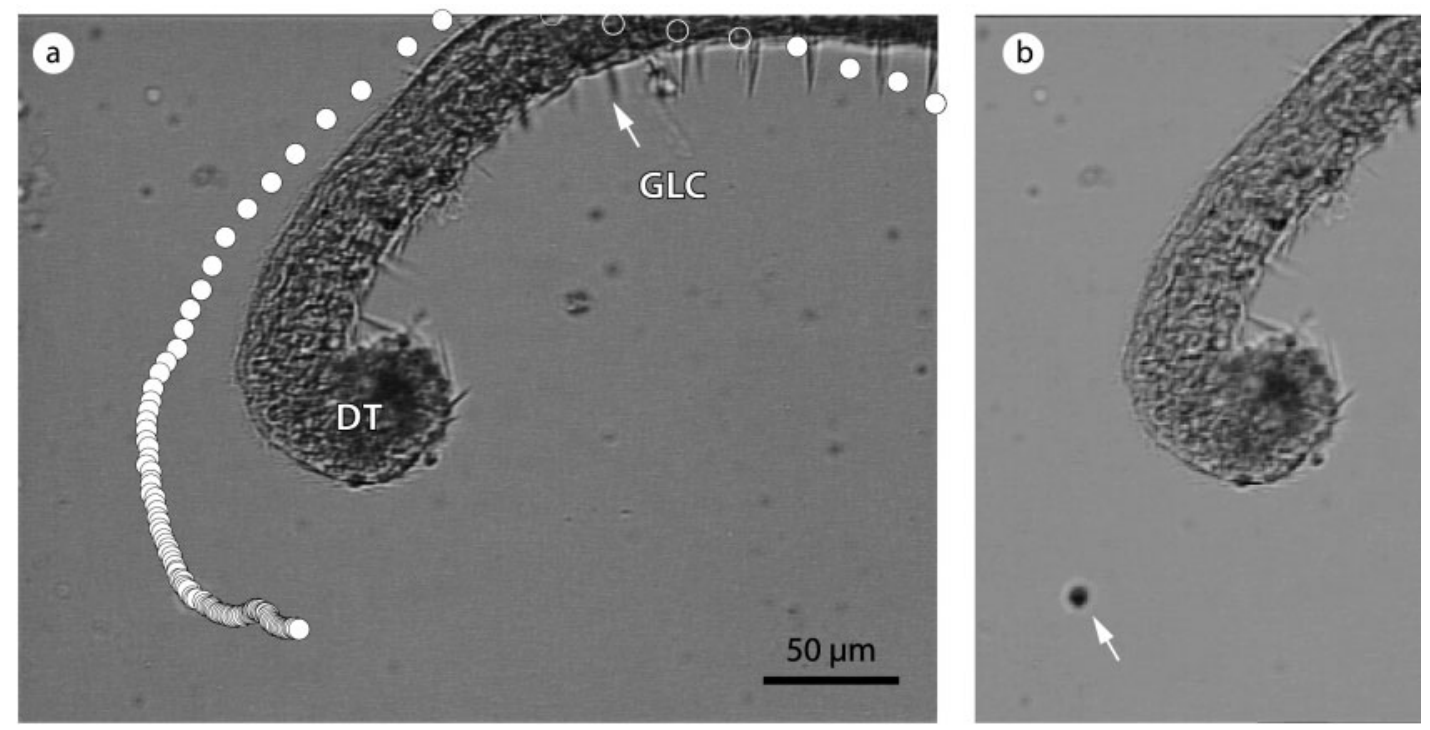

Fig. 5. Sabellaria alveolata. (a) Latero-abfrontal view of a tentacle and its distal tip (DT). Trajectory of a particle led into the ciliary current generated by motion of grouped lateral cilia (GLC) and the frontal ciliary band of the tentacle during approximately $10 \mathrm{~s}$. Each white circle represents the position of the particle of Coscinodiscus granii separated by 0.08 s. Open circles indicate that the particle is behind the tentacle and not entirely visible. (b) Video still print showing tentacle and particle (white arrow) without digital treatment 

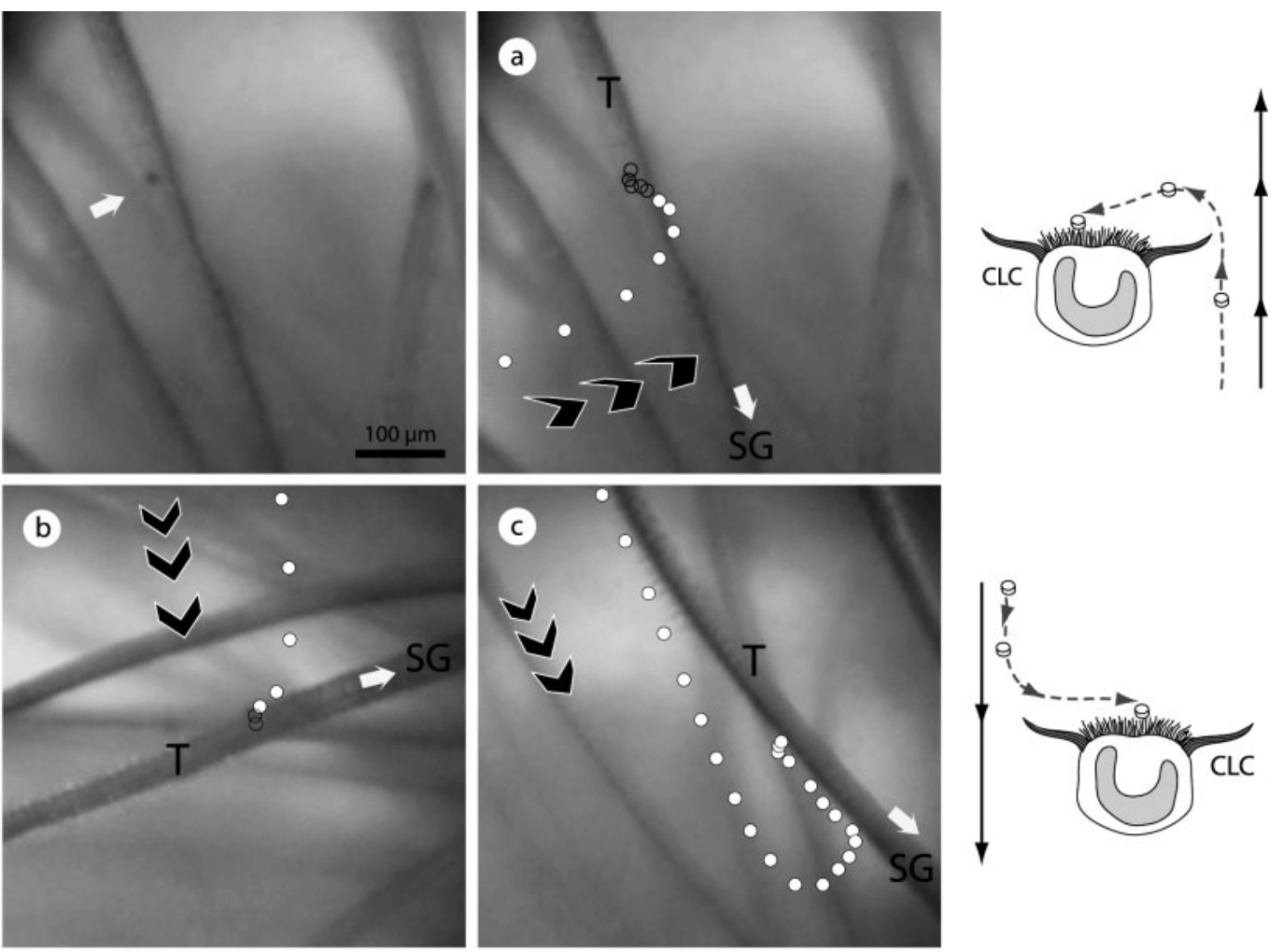

Fig. 6. Sabellaria alveolata. Types of trajectory of particles before being captured by the frontal surface of the tentacle. Each white circle represents the position of the particle of Coscinodiscus granii separated by $0.08 \mathrm{~s}$. Open circles indicate that the particle is behind the tentacle (T) and not visible (black arrows, direction of the current transporting particles; grey arrows, currents generated by grouped lateral cilia [CLC]; white arrows, toward the secondary groove [SG]): (a) downstream particle retention, (b) upstream particle retention and (c) upstream particle retention with broken particle trajectory. Explanatory drawings of downstream and upstream retention mechanisms to the right. In the upper left corner, video still print of filament and particle without digital treatment

Upstream collecting of particles was also observed (Fig. $6 \mathrm{~b}, \mathrm{c})$. In the same way as downstream particle retention, particles that entered the region swept by lateral cilia were directed towards the ciliated surface. One characteristic feature of upstream particle capture in recordings was that the paths of particles entering the tentacle wreath were slowed down before the particles impacted and stuck to a tentacle. We recorded a broken trajectory (Fig. 6c) as if the currents between tentacles were interrupted and reversed.

Moreover, when worms were feeding at high particle concentrations $\left(4 \times 10^{5}\right.$ cells ml $\left.{ }^{-1}\right)$, regular inward flicking of tentacles was observed, both individual tentacle flicking as well as simultaneous flicking of all the tentacles. This was seen when the ciliary band was loaded with numerous or large particles. The frequency of observation was very variable, but increased with particle concentration. This mechanism occurs also when a shell fragment or a large mineral particle (>5 $\mathrm{mm}$ in length) hits the tentacle. Video recordings of the 2 palps showed that they could not only collect par- ticles, but also clean the tentacle area. Some frictions have been observed between palps and tentacles.

\section{Transport of particles and production of pseudofaeces}

Ciliary tracts along tentacles and in grooves produced surface currents that emerged into the feeding current terminating in the oesophagus. The processing speed was very variable depending on particle concentration. At the initial, low particle concentration $\left(5 \times 10^{3}\right.$ cells ml $\left.{ }^{-1}\right)$, speeds were measured between 0.1 and $0.3 \mathrm{~mm} \mathrm{~s}^{-1}$ for Coscinodiscus granii cells. At the higher particle concentration (approx. $4 \times 10^{5}$ cells $\left.\mathrm{ml}^{-1}\right)$, speeds measured on tentacles were slowest (max. $0.1 \mathrm{~mm} \mathrm{~s}^{-1}$ ) and did not appear to be influenced by particle quality (organic vs. inorganic), size (from 10 to $60 \mu \mathrm{m}$ ), or shape (spherical or rod-shaped). At the higher particle concentration, bidirectional transport on the tentacle was observed. Particles initially trans- 
ported towards the proximal part of the tentacle and the secondary groove were suddenly directed in the opposite direction, reaching the distal tip before being ejected by a releasing mechanical movement of the tentacle. When the direction of particle transport is reversed, particle speed can reach $0.2 \mathrm{~mm} \mathrm{~s}^{-1}$.

When collected by the secondary and the primary grooves, particles are transported to the mouth at the lowest speed of approximately $0.1 \mathrm{~mm} \mathrm{~s}^{-1}$. Fig. 7 shows the steps in the formation of pseudofaeces: particles are accumulated within the primary grooves and transported to the mouth. The borders of the grooves are very flexible and can maintain large particles such as sand grains or shell fragments of a few millimetres. When in the buccal cavity, particles may stay for some seconds to $>1 \mathrm{~min}$, depending on the degree of buccal fullness. The content of the buccal cavity is then manipulated by the lips, and the aggregated particles are expelled. Motile cilia on the cephalic floor play an important role in the ejection of pseudofaeces. Recordings showed mucus strings that are expelled from the worms in the water column at a velocity of 2 to $3 \mathrm{~mm}$ $\mathrm{s}^{-1}$. Moreover, positions between secondary grooves are alternative sites for the rejection of particles that escape the grooves. In such cases, we recorded speeds of 2 or $3 \mathrm{~mm} \mathrm{~s}^{-1}$ for both single particles and small aggregates.

\section{DISCUSSION}

\section{Particle capture in sabellariids}

The characteristics and organisation of feeding organs of Sabellaria alveolata contrast with those described for pinnules in the sabellids Sabella penicillus (Riisgård \& Ivarsson 1990) and Euchone papillosa (Riisgård et al. 2002), or the serpulid Ditrupa arietina (Riisgård et al. 2002). Sabellids and serpulids have a higher level of complexity in their feeding structures compared to sabellariids: they have lobes curved around on either side of the mouth and bear tentacles over almost $360^{\circ}$, which stand out stiffly at regular intervals. Each tentacle carries a double row of pinnules, which are similar to what are called tentacles in sabellariids. Such a complex organisation requires rigid structures, whereas the tentacles of $S$. alveolata are very flexible and the worm flicks these tentacles when withdrawing into its tube. These morphological and geometrical considerations have consequences on the currents within the tentacle-crown.

As demonstrated by video recordings, particle capture mechanisms in sabellariids are based on the catch-up principle (Riisgård et al. 2000): the grouped lateral cilia constitute the pump, which generates a flow with suspended particles that enter the ciliary
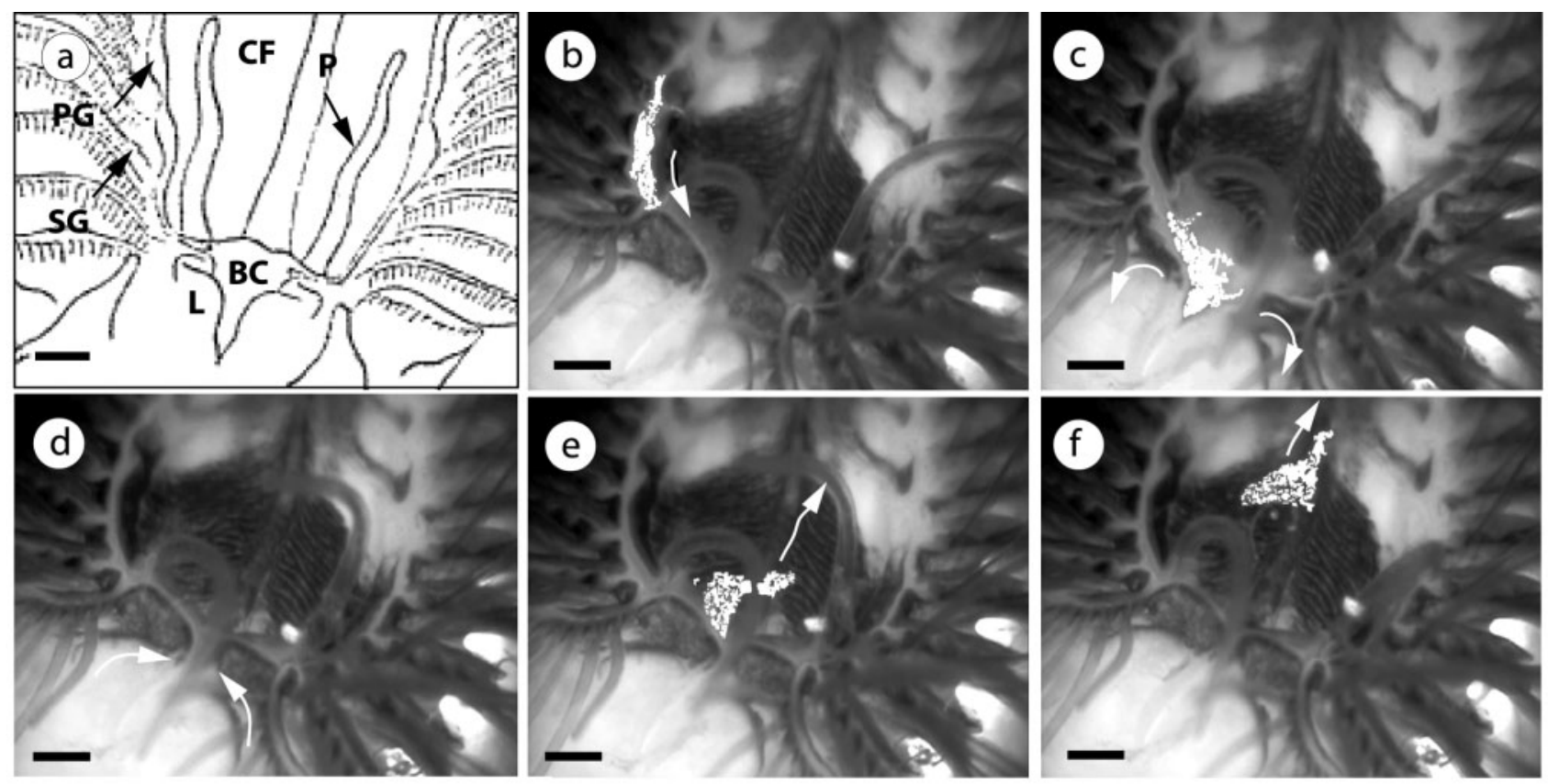

Fig. 7. Sabellaria alveolata. Video endoscopic still prints showing formation of pseudofaeces (highlighted by image analysis). White arrows follow description of processes. (a) Explanatory drawing of video prints showing feeding organs involved (for legend, see Fig. 1). (b) Accumulation of food transported within primary grooves and coming from several secondary grooves. (c) Opening of lips and entrance of food within the buccal cavity. (d) Treatment of food. Note the shutting of the lips. (e) Rejection of particles embedded in mucus and falling on the cephalic floor. (f) Expulsion of the pseudofaeces under motion of motile ciliary bands on the cephalic floor. Scale bar $=1 \mathrm{~mm}$; time elapsed $=45 \mathrm{~s}$ 
region. During their power stroke, the cilia intercept particles and transfer them to the frontal ciliary band before they are collected by the grooves. Both downstream and upstream collecting mechanisms have been shown in Sabellaria alveolata. One explanation for the observation of these 2 types of mechanisms is the motility of tentacles and the motility of the animal in its tube. The worm generally faces the prevailing current and thus uses downstream collecting mechanisms to collect particles. By the movement of tentacles and by a change in the general orientation of the tentacle-crown, the prevailing current entering the tentacle-crown is altered and some of the trapped particles seem to be transported by opposing currents before being stuck on tentacles. This appears to explain why particles approaching the tentacle sometimes move through an arc of $180^{\circ}$ before being stuck on the ciliary surface. A similar trajectory has been observed in the serpulid Spirorbis tridentatus (Riisgård et al. 2000). It will be of great interest to better understand how patterns of currents are structured within the tentaclecrown.

As shown by SEM photographs, grouped lateral cilia are evenly spaced by approximately $30 \mu \mathrm{m}$. According to the catch-up principle (Riisgård et al. 2000), the lower limit of the particle-size spectrum depends on the spacing between cilia in phase, which is at least $30 \mu \mathrm{m}$ in Sabellaria alveolata. Dubois et al. (2003) have shown that particles $>5 \mu \mathrm{m}$ (ESD) can be retained with an efficiency of $100 \%$, leading to the conclusion that downstream collecting is not the only mechanism involved in $S$. alveolata feeding. Tentacle flicking movements are probably responsible for the alteration of currents within the tentacle-crown and help in particle capture. Thus, the characteristic features of particle capture in $S$. alveolata have strong similarities with those observed and described in lophophorids (McKinney 1990, Riisgård \& Manriquez 1997). Even in terms of morphology, similarities between sabellariids and ectoprocts can be noted: the lophophore consists of a ring of extended ciliated tentacles, which form a tentacular crown, with the mouth at the centre of its base. It is hypothesised here that $S$. alveolata displays some of the same feeding mechanisms as those of lophophorids (phoronids, brachiopods and bryozoans), while others are in common with other ciliary filter-feeding polychaetes (sabellids and serpulids).

Sabellids and serpulids bear both lateral compound cilia and latero-frontal cilia, whereas only grouped lateral cilia occur in sabellariids. These strong and rigid structures carry a larger number of cilia than in other ciliary filter-feeding polychaete families. We suggest here that grouped lateral cilia in Sabellaria alveolata are more efficient in creating surface currents than those of sabellids, because of the higher tip particle velocities measured in the ciliary region (2.1 vs. $1.25 \mathrm{~mm} \mathrm{~s}^{-1}$ in Sabella penicillus, Mayer 1994).

In addition to random single movements, metachronal waves moving from the proximal part to the distal tip of the tentacle were observed. It is now accepted that metachronal co-ordination is due to mechanical or hydrodynamic forces acting between cilia (Okamoto \& Nakaoka 1994). The role of such metachronal waves is still being investigated, but we hypothesise here a role in particle transport as suggested below.

\section{Particle transport in sabellariids}

Latero-frontal cilia are known to have an important role in deflecting particles onto the frontal ciliary band in bivalves (Silverman et al. 1996) as well as in polychaetes (Riisgård et al. 2002). In Sabellaria alveolata, particles deflected onto the frontal cilia remain on this tract and are transported toward the secondary and primary grooves. It is possible that the lack of latero-frontal cilia in $S$. alveolata is representative of a primitive condition in the evolution of ciliary structures in filter-feeding polychaetes. This has been suggested by Beninger et al. (2003) for the bivalve Bathypecten vulcani, whose gills have no latero-frontal cilia, unlike all other autobranch bivalves described to date.

Without latero-frontal cilia, the role of mucus in the capture of particles is of primary importance. This has been underlined for spionids (Dauer 1983, 1985, Qian \& Chia 1997, Shimeta \& Koehl 1997), which have a pair of palps and can feed either as deposit feeders on the sediment surface or as suspension feeders on suspended particles, but cannot be considered as ciliary suspension feeders only. We have demonstrated here fundamental differences in mucocyte assemblages between tentacles and grooves that conduct collected particles to the mouth. Once particles have been collected on tentacles through cilia currents, they are stuck with high viscosity mucus. Viscous acid or acid-dominant mucopolysaccharides are used when particle transport occurs on an exposed surface, such as in the ordinary filament crest of the gill in the scallop (Beninger et al. 1993), the oyster Crassostrea virginica (Beninger \& Dufour 1996), or the frontal filament of the gill in the blue mussel Mytilus edulis (Beninger et al. 1993). Sabellaria alveolata tentacles show exclusively acid mucocytes that are well adapted to this worm's biological constraints: it usually lives on an exposed shore, where waves and hydrodynamics are strong enough to resuspend sand particles and shell fragments. The tentacles of the worm are exposed to stronger currents than the gills of bivalves: particles on gills are exposed to siphonal currents, whereas 
particles on tentacles are directly exposed to currents in the water column. Particles stuck on tentacles would therefore require a high-viscosity mucus to avoid resuspension. It is thus particularly remarkable that mucocyte density is 2 or 3 times higher in $S$. alveolata than in bivalve gills in general (see Beninger \& St-Jean 1997a for a review).

The speed of transport on tentacles in Sabellaria alveolata is close to the speed assessed in equivalent structures (i.e. pinnules) in Sabella penicillus (Mayer 1994) under similar experimental conditions (0.1 to $0.3 \mathrm{~mm} \mathrm{~s}^{-1}$ in $S$. alveolata vs. 0.05 to $0.15 \mathrm{~mm} \mathrm{~s}^{-1}$ in $S$. penicillus). We supposed equivalent mucocyte distribution between pinnules and tentacles. When exposed to high concentrations of algae, lower transport velocities were measured, probably caused by an increase in mucus secretion. Moreover, we showed that particles, instead of being transported towards the secondary grooves, could be transported towards the distal tip of tentacles. Metachronal waves could play a role in conducting particles towards the distal tip of the tentacle by creating a surface current opposed to the frontal ciliary motion. This could be a mechanism to clear grooves when the degree of filling was too high.

Transport in secondary and in primary grooves was similar: mucocyte distribution and cilia patterns were identical, and we found that the mucus layer within the grooves was constituted only by acid mucopolysaccharides. According to Beninger \& St-Jean (1997a), enclosed surfaces, such as the ventral groove of gills in bivalves, present a lower viscosity and mixed mucus secretion type. As mentioned above, this mucus distribution is probably an adaptation of sabellariids to more disruptive hydrodynamic conditions, but may also correspond to indiscriminate transport for later selection of particles.

Video observations and histological data revealed that the cephalic floor was the main structure involved in pseudofaeces rejection. Speeds of rejection were measured at $3 \mathrm{~mm} \mathrm{~s}^{-1}$. High speeds were due to mixed mucocytes (localised for example on external borders of the primary grooves), with a lower viscosity of mucus secretion and the presence of long motile ciliary bands. The same mucocyte distribution was seen on the external borders of secondary grooves leading to the conclusion that areas between secondary grooves represented another path of rejection of pseudofaeces. Once in the buccal cavity, particles are embedded in mucus by lips and are rejected onto the cephalic floor or ingested with the help of fluid mucus (neutral mucocytes), as demonstrated for bivalves (Beninger \& S-Jean 1997b). To our knowledge, the presence of pseudofaeces in sabellariids and in ciliary filter-feeding polychaetes has never been mentioned in the literature. The production of pseudofaeces is an adaptation to high particle concentrations. Indeed, species that produce pseudofaeces could continue to feed whatever the particle concentration.

The role of the palps in Sabellaria alveolata remains to be investigated. We showed that they could participate in the capture and transport of particles, but are also involved in cleaning tentacles and organs embedded in algal filaments or overloaded by particles. These palps are seen as a multifunctional and manoeuvrable organ in sabellariid competent larvae (Amieva \& Reed 1987), and may be qualified in the same way for adults. From data related to the nervous system, Orrhage (1978) has shown that the palps of sabellariids are homologous to those of spionids.

\section{CONCLUSIONS}

This study represents the first step in the elucidation of feeding mechanisms of sabellariids. Downstream collecting systems have been demonstrated and described in sabellids and serpulids, but not yet in the third ciliary suspension-feeding family of the polychaete sabellariids. All 3 families constitute a special feeding group for Rouse \& Fauchald (1997), who distinguished polychaete phylogenetic relationships according to a possible scenario for the evolution of buccal organs. However, from all the evidence, morphological and functional differences lead to the conclusion that, in terms of mechanisms involved in feeding processes, sabellariids are no closer to sabellids and serpulids than they are to lophophorids.

Acknowledgements. The authors wish to thank Dr. Y. Gruet for his help and comments. S.D. is grateful to the entire staff of the Marine Biology Laboratory of the University of Nantes for provision of facilities, algal cultures and for technical help and expertise.

\section{LITERATURE CITED}

Amieva MR, Reed CG (1987) Functional morphology of the larval tentacles of Phragmatopoma californica (Polychaeta: Sabellariidae): composite larval and adult organs of multifunctional significance. Mar Biol 95:243-258

Barillé L, Prou J, Héral M, Bougrier S (1993) No influence of food quality, but ration-dependent retention efficiencies in the Japanese oyster Crassostrea gigas. J Exp Mar Biol Ecol 171:91-106

Beninger PG, Dufour SC (1996) Mucocyte distribution and relationship to particle transport on the pseudolamellibranch gill of Crassostrea virginica (Bivalvia: Ostreidae). Mar Ecol Prog Ser 137:133-138

Beninger PG, St-Jean S (1997a) The role of mucus in particle processing by suspension-feeding marine bivalves: unifying principles. Mar Biol 129:389-397

Beninger PG, St-Jean S (1997b) Particle processing on the labial palps of Mytilus edulis and Placopecten magellanicus (Mollusca: Bivalvia). Mar Ecol Prog Ser 147:117-127

Beninger PG, Ward JE, MacDonald BA, Thompson RJ (1992) 
Gill function and particle transport in Placopecten magellanicus (Mollusca: Bivalvia) as revealed using video endoscopy. Mar Biol 114:281-288

Beninger PG, St-Jean S, Poussart Y, Ward JE (1993) Gill function and mucocyte distribution in Placopecten magellanicus and Mytilus edulis (Mollusca: Bivalvia). Mar Ecol Prog Ser 98:275-282

Beninger PG, Donval A, Le Pennec M (1995) The osphradium in Placopecten magellanicus and Pecten maximus (Bivalvia: Pectinidae): histology, ultrastructure and implications for spawning synchronisation. Mar Biol 123:121-129

Beninger PG, Dufour SC, Decottignies P, Le Pennec M (2003) Particle processing mechanisms in the archaic, perihydrothermal vent bivalve Bathypecten vulani, inferred from cilia and mucocyte distributions on the gill. Mar Ecol Prog Ser 246:183-195

Beninger PG, Decottignies P, Rincé Y (2004) Localization of quantitative particle selection sites in the heterorhabdic filibranch Pecten maximus (Bivalvia: Pectinidae). Mar Ecol Prog Ser 275:163-173

Boyde A, Wood C (1969) Preparation of animal tissues for surface-scanning electron microscopy. J Microsc 90:221-249

Cognie B, Barillé L, Massé G, Beninger PG (2003) Selection and processing of large suspended algae in the oyster Crassostrea gigas. Mar Ecol Prog Ser 250:145-152

Dauer DM (1983) Functional morphology and feeding behavior of Scolelepis squamata (Polychaeta: Spionidae). Mar Biol 77:279-285

Dauer DM (1985) Functional morphology and feeding behavior of Paraprionospio pinnata (Polychaeta: Spionidae). Mar Biol 85:143-151

Dubois S, Retière C, Olivier F (2002) Biodiversity associated with Sabellaria alveolata (Polychaeta: Sabellariidae) reefs: effects of human disturbances. J Mar Biol Assoc UK 82: $817-826$

Dubois S, Barillé L, Retière C (2003) Efficiency of particle retention and clearance rate in the polychaete Sabellaria alveolata L. CR Biol 326:413-421

Dufour SC, Beninger PG (2001) A functional interpretation of cilia and mucocyte distributions on the abfrontal face of bivalve gills. Mar Biol 138:295-309

Fauchald K, Jumars PA (1979) The diet of worms: a study of polychaete feeding guilds. Oceanogr Mar Biol Annu Rev 17:193-284

Gruet Y (1982) Recherches sur l'écologie des 'récifs' d'Hermelles édifiés par l'annélide polychète Sabellaria alveolata (Linné). PhD thesis, Université des Sciences et Techniques, Nantes

Gruet Y (1984) Granulometric evolution of the sand tube in relation to growth of the polychaete annelid Sabellaria alveolata (Linné) (Sabellariidae). Ophelia 23:181-193

Hochberg R, Litvaitis MK (2000) Hexamethyldisilazane for scanning electron microscopy of Gastrotricha. Biotech Histochem 75:41-44

Holt TJ, Rees EI, Hawkins SJ, Seed R (1998) Biogenic reefs, Vol 9: an overview of dynamic and sensitivity characteristics for conservation management of marine SACs. UK Marine SACs Project, Scottish Association for Marine Science, Oban

Johansson KE (1927) Beiträge zur Kenntnis der Polychaeten Familien Hermellidae, Sabellidae und Serpulidae. ZOON (Upps) 11:1-184

Jørgensen CB, Kiørboe T, Mohlenberg F, Riisgård HU (1984) Ciliary and mucus-net filter feeding, with special reference to fluid mechanical characteristics. Mar Ecol Prog Ser 15:283-292

Martoja R, Martoja M (1967) Initiation aux techniques de l'histologie animale. Masson et Cie, Paris

Mayer S (1994) Particle capture in the crown of the ciliary suspension feeding polychaete Sabella penicilus: videotape recordings and interpretations. Mar Biol 119:571-582

Mayer S (2000) Numerical simulation of flow fields and particle trajectories in ciliary suspension feeding. Bull Math Biol 62:1035-1059

McKinney FK (1990) Feeding and associated colonial morphology in marine bryozoans. Rev Aquat Sci 2:255-288

Nation JL (1983) A new method for using hexamethyldisilazane for preparation of soft insect tissues for scanning electron microscopy. Stain Technol 58:347-351

Okamoto KI, Nakaoka Y (1994) Reconstitution of metachronal waves in ciliated cortical sheets of Paramecium. J Exp Biol 192:61-72

Orrhage L (1978) On the structure and evolution of the anterior end of the Sabellariidae (Polychaeta: Sedentaria): with some remarks on the general organisation of the polychaete brain. Zool Jahrb Abt Anat 100:343-374

Pawlick JR (1988) Larval settlement and metamorphosis of sabellariid polychaetes, with special reference to Phragmatopoma lapidosa, a reef-building species, and Sabellaria floridensis, a non-gregarious species. Bull Mar Sci 43:41-60

Qian PY, Chia FS (1997) Structure of feeding palps and feeding behavior of the spionid polychaete Polydora polybranchia. Bull Mar Sci 60:502-511

Riisgård HU, Irvarsson NM (1990) The crown-filament-pump of the suspension feeding polychaete Sabella penicilus: filtration, effects of temperature, energy cost, and modelling. Mar Ecol Prog Ser 62:249-257

Riisgård HU, Larsen PS (1995) Filter-feeding in marine macro-invertebrates: pump characteristics, modelling and energy cost. Biol Rev 70:67-106

Riisgård HU, Larsen PS (2000) Comparative ecophysiology of active zoobenthic filter feeding, essence of current knowledge. J Sea Res 44:169-193

Riisgård HU, Manriquez P (1997) Filter-feeding in fifteen marine ectoprocts (Bryozoa): particle capture and water pumping. Mar Ecol Prog Ser 154:223-239

Riisgård HU, Nielsen C, Larsen PS (2000) Downstream collecting in ciliary suspension feeders: the catch-up principle. Mar Ecol Prog Ser 207:33-51

Riisgård HU, Grémare A, Amouroux JM, Charles F, Vétion G, Rosenberg R, Nielsen C (2002) Comparative study of water-processing in two ciliary filter-feeding polychaetes (Ditrupa arietina and Euchone papillosa) from two different habitat. Mar Ecol Prog Ser 229:113-126

Rouse G, Fauchald K (1997) Polychaete systematics: past and present. Zool Scr 26:71-138

Rubenstein DI, Koel MAR (1977) The mechanisms of filter feeding: some theoretical considerations. Am Nat 111:981-994

Shimeta J, Koehl MAR (1997) Mechanisms of particle selection by tentaculate suspension feeders during encounter, retention, and handling. J Exp Mar Biol Ecol 209:47-73

Silverman H, Lynn JW, Dietz TH (1996) Particle capture by gills of Dreissena polymorpha: structure and function of laterofrontal cirri. Biol Bull (Woods Hole) 191:42-54

Ward JE, Beninger PG, MacDonald BA, Thompson RJ (1991) Direct observations of feeding structures and mechanisms in bivalve molluscs using endoscopic examination and video image analysis. Mar Biol 111:287-291

Ward JE, MacDonald BA, Thompson RJ, Beninger PG (1993) Mechanisms of suspension feeding in bivalves: resolution of current controversies by means of endoscopy. Limnol Oceanogr 38:265-272

Wells RMG (1970) The feeding biology of Sabellaria. Tane 16: 131-134

Submitted: February 25, 2005; Accepted: June 11, 2005

Proofs received from author(s): September 6, 2005 